\title{
PHYTOCHEMISTRY, TOXICITY AND EFFICACY OF CRUDE AQUEOUS EXTRACT OF CARICA PAPAYA LEAF AGAINST TRYPANOSOMA BRUCEI
}

\author{
A. A. Biu ${ }^{1}$, L. B. Buratai ${ }^{2}$, A. A. Ahmad ${ }^{2}$, I. U. Hambali ${ }^{3}$, S. I. Ngulde ${ }^{4 *}$, M. Zakariah ${ }^{5}$ and J. R. Lawal ${ }^{6}$ \\ ${ }^{1}$ Department of Veterinary Microbiology and Parasitology, Faculty of Veterinary Medicine, ${ }^{2}$ Department of \\ Biochemistry, Faculty of Science, ${ }^{3}$ Department of Veterinary Public Health and Preventive Medicine, \\ ${ }^{4}$ Department of Veterinary Physiology, Pharmacology and Biochemistry, ${ }^{5}$ Department of Veterinary Anatomy, \\ ${ }^{6}$ Department of Veterinary Medicine, Faculty of Veterinary Medicine, University of Maiduguri, Nigeria
}

\begin{abstract}
The aqueous extract of Carica papaya leaf was evaluated for its phytochemistry, acute toxicity and in vitro antitrypanosomal efficacy in this study. A total of 15 albino rats grouped into 5(A-E) of 3 rats each were intraperitoneally treated with graded doses of $100,200,400,800 \mathrm{mg} / \mathrm{kg}$ body weight of the aqueous extract and observed for 24 hours for clinical signs and death. The calculated median lethal dose $\left(\mathrm{LD}_{50}\right)$ was $600 \mathrm{mg} / \mathrm{kg}$ body weight, with clinical signs of sluggishness, awkward pasture, loss of appetite, starry hair coat and terminal death within 24 hours. Severity of clinical signs varied with increasing doses. The in vitro antitrypanosomal efficacy of the aqueous extract showed $100 \%$ inhibition of Trypanosoma brucei at concentrations of $40 \mathrm{mg} / \mathrm{ml}, 20 \mathrm{mg} / \mathrm{ml}, 10 \mathrm{mg} / \mathrm{ml}, 5 \mathrm{mg} / \mathrm{ml}$ and $2.5 \mathrm{mg} / \mathrm{ml}$ respectively. In conclusion the aqueous extract of $C$. papaya leaf has bioactive components that are moderately toxic and has trypanosomal inhibitory activity.
\end{abstract}

Keywords: Carica papaya, phytochemistry, acute toxicity, in vitro efficacy, Trypanosoma brucei

\section{INTRODUCTION}

African trypanosomiasis, also known as African sleeping sickness is one of the neglected diseases in about thirty-six countries of sub-Saharan Africa threatening about 40 million human lives (Tyler and Steverding, 2005). Trypanosoma brucei, a haemo-protozoan parasite transmitted by tsetse fly causes the disease (Moore, 2005). There are about 23 species of tsetse in sub-Saharan Africa primarily Glossina morsitans, G. palpalis, G. fusca. In Nigeria, animal trypanosomiasis is widely distributed from mangrove forest to Sudan savannah due to presence of the tsetse flies in this area (Rocha et al., 2004; Moore, 2005). The economic importance of the disease includes high morbidity, mortality, lower efficiency and high cost of treatment (Brun et al., 2010). The current chemotherapy in humans and animals relies on suramin, pentamidine, melasoprol, eflorithine and diminazene aceturate (Sofowora, 1993). It has been observed that natural products derived from plants offer novel possibilities to obtain new drugs that are active against trypanosomes (Hoet et al., 2004).

Carica papaya belongs to the family Caricacea, and several species of Caricaceae have been used as remedy against a variety of diseases (Mello et al., 2008). Derived from the southern part of Mexico, Carica papaya is a perennial plant and distributed over the whole tropical area. Many scientific investigations have been conducted to evaluate the biological activities of various parts of $C$. papaya including its fruits, shoots, leaves, rinds, seeds, roots or latex (Munox et al., 2000). The leaf of $C$. papaya has been shown to contain many active components that can increase the total antioxidant power in blood and reduce lipid peroxidation level. This study was conducted to evaluate the in vitro trypanosomal inhibitory activity of $C$. papaya.

\section{MATERIALS AND METHODS}

Fresh leaves of $C$. papaya were collected within University of Maiduguri Campus in Nigeria and authenticated by a botanist in the Faculty of Science, University of Maiduguri, Nigeria. The fresh leaves of C. papaya were rinsed in clean water and air dried in the laboratory for 1 week at room temperature, ground into fine powder using pestle and mortar and sieved to remove debris and coarse plant materials.

*Corresponding e-mail address: singulde@gmail.com

Copyright (c) 2016 Bangladesh Society for Veterinary Medicine 


\section{A. A. Biu and others}

A 1000 gram pre-extraction weight was obtained, which was soaked in 3litres of distilled water, shaken at regular intervals and then filtered using Whatman's number 1 paper. The filtrate was evaporated at $35-40^{\circ} \mathrm{C}$ in a water bath, allowed to dry on a hot plate and ground using pestle and mortar to obtain a $74.69 \mathrm{~g}$ powder used for the study. Tests were carried out for tannins, alkaloids, saponins, steroids, phlabotannins, glycosides, flavonoids, free anthraquinones, reducing sugars and ketones as described by Trease and Evans, (2002). Fifteen albino rats obtained from the animal breeding house, University of Maiduguri were used for the study. The rats were kept in a well-ventilated Laboratory and were fed with a commercial poultry feed and given water ad libitum. Trypanosoma brucei was obtained from Nigeria Institute of Trypanosomiasis Research (NITR), Vom, Plateau State, Nigeria. The Trypanosome was passaged in donor rats before infection of the experimental rats, intraperitoneally with $0.1 \mathrm{ml}$ of saline diluted blood containing $1.5 \times 10^{6}$ trypanosomes. The level of parasitaemia was determined using the rapid matching method of Herbert and Lumsden (1976). Fifteen albino rats were grouped into 5 (A-E) of 3 rats each and weighed in kilogram $(\mathrm{kg})$ and marked with an ink blotter for easy identification. The rats were intraperitoneally treated with graded doses of $100,200,400$ and $800 \mathrm{mg} / \mathrm{kg}$ of the extract based on method of Karber as modified by Aliu and Nwude (1982). The concentration used was $100 \mathrm{mg} / \mathrm{ml}$. The rats were observed within $24 \mathrm{hrs}$ for clinical signs. The $\mathrm{LD}_{50}$ of Carica papaya was then calculated using the modified arithmetic method (Aliu and Nwude, 1982). A serial dilution of the extract (40, 20, $10,5,2.5,1.25,0.625,0.313,0.156$ and $0.078 \mathrm{mg} / \mathrm{ml}$ ) was prepared in a phosphate buffered saline solution (PBGS) in different test tubes. Two drops of blood containing the parasite $\left(2 \times 10^{6}\right)$ was added into each test tube and incubated at $37^{\circ} \mathrm{C}$. The number of motile parasites was counted under the light microscope using improved Neubauer's chamber at 10, 30, 60, 90 and 120 minutes post incubation. The percentage inhibition of motility of the parasite was calculated using this formula below:

$\%$ inhibition $=($ Parasite count of control - Parasite count of treated $/$ Parasite count of control $) \times 100$

\section{Statistical analysis}

Inhibition of motility values were expressed as mean \pm standard deviation (SD) and percentages.

\section{RESULTS AND DISCUSSION}

Flavonoids, alkaloids, steroids, monosacharides, reducing sugars and phlabotannins, free anthraquinones and glycosides were present but saponins was not detected (Table 1).

Table 1. Phytochemical components of crude aqueous extract of Carica papaya leaf

\begin{tabular}{llll}
\hline Component & Test & Observation & Scoring \\
\hline Alkaloids & Dragendorff's & Brownish precipitate & + \\
Flavonoids & Pew's & Red colour & + \\
Anthraquinones & Borntrager's & Violet colour & + \\
Steroids & Acetic anhydride & Green colour & + \\
Saponins & Frothing & Persistent foaming & - \\
Reducing sugar & Fehling's & Brick red precipitate & + \\
Phlabotannins & Hydrogen chloride & Red precipitate & + \\
Monosaccharide & Barfoed's & Red precipitate & + \\
Glycosides & Salkowski's & Reddish brown colour & + \\
\hline
\end{tabular}

$+=$ detected $-=$ not detected

The dose of the extracts that produced $100 \%$ mortality of treated albino rats was $800 \mathrm{mg} / \mathrm{kg}$. There were dose dependent clinical signs of sluggishness, awkward pasture, loss of appetite, starry hair coat and terminal death within 24 hours. At doses of 100, 200 and $400 \mathrm{mg} / \mathrm{kg}$, mortality was not recorded (Table 2). There was significant $(\mathrm{p}<0.05)$ decline in mean count $\left(\times 10^{6}\right)$ of $T$. brucei with increase in extract concentration when compared with the normal control. Table 4 shows the in vitro percentage inhibition of $T$. brucei by crude aqueous extract of Carica papaya leaf. There was $100 \%$ inhibition of motility of T. brucei at the extract concentration of $2.5 \mathrm{mg} / \mathrm{ml}$ between 60 and 120 post inoculations; meanwhile the various extract concentrations generally had a positive correlation with inhibition of motility of $T$. brucei. 
Aqueous extract of Carica papaya leaf on Trypanosoma brucei

Table 2. Lethal Dose $\left(\operatorname{ld}_{50}\right)$ of crude aqueous extract of Carica papaya leaf in albino rats

\begin{tabular}{|c|c|c|c|c|c|}
\hline Group (N=3) & $\begin{array}{l}\text { Plant Extract }(\mathrm{mg} / \mathrm{Kg} \\
\text { Body Weight })\end{array}$ & $\begin{array}{l}\text { Dose Difference } \\
\text { (DD) }\end{array}$ & Number Dead & Mean Dead (MD) & DD x MD \\
\hline \multirow[t]{2}{*}{ A } & 100 & & 0 & & \\
\hline & & $B-A=100$ & & 0 & 0 \\
\hline \multirow[t]{2}{*}{ B } & 200 & & 0 & & \\
\hline & & $C-B=200$ & & 0 & 0 \\
\hline \multirow[t]{2}{*}{$\mathrm{C}$} & 400 & & 0 & & \\
\hline & 800 & $\mathrm{D}-\mathrm{C}=400$ & 3 & 1.5 & 600 \\
\hline Total & & & & & 600 \\
\hline
\end{tabular}

$\mathrm{LD}_{50}=\mathrm{LD}_{100}-(\mathrm{DD} \times \mathrm{MD} / \mathrm{n})=800-(600 / 3)=600 \mathrm{mg} / \mathrm{kg}$ weight

Table 3. In vitro efficacy of crude aqueous extract of Carica papaya leaf against Trypanosoma brucei

\begin{tabular}{lllll}
\hline $\begin{array}{c}\text { Concentration of Extract } \\
(\mathrm{mg} / \mathrm{ml})\end{array}$ & \multicolumn{3}{c}{ Parasite Count Minutes Post Inoculation $(\mathrm{MPI})\left(\mathrm{x} 10^{6}\right)$} \\
\cline { 2 - 5 } & $30 \mathrm{mins}$ & $60 \mathrm{mins}$ & $90 \mathrm{mins}$ & $120 \mathrm{mins}$ \\
\hline PBGS (Control) & $1.89 \pm 0.06$ & $1.94 \pm 0.09$ & $2.16 \pm 0.21$ & $2.14 \pm 0.15$ \\
& $(1.85-1.83)$ & $(2.05-1.85)$ & $(2.45-1.95)$ & $(2.35-2.05)$ \\
0.078 & $0.61 \pm 0.04$ & $0.55 \pm 0.08$ & $0.58 \pm 0.02$ & $0.52 \pm 0.02$ \\
& $(0.65-0.75)$ & $(0.63-0.46)$ & $(0.61-0.57)$ & $(0.55-0.50)$ \\
0.156 & $0.51 \pm 0.02$ & $0.46 \pm 0.03$ & $0.36 \pm 0.02$ & $0.31 \pm 0.02$ \\
& $(0.53-0.49)$ & $(0.49-0.43)$ & $(0.38-0.35)$ & $(0.34-0.30)$ \\
0.313 & $0.40 \pm 0.05$ & $0.33 \pm 0.04$ & $0.27 \pm 0.01$ & $0.22 \pm 0.01$ \\
& $(0.4-0.35)$ & $(0.38-0.30)$ & $(0.29-0.26)$ & $(0.23-0.21)$ \\
0.625 & $0.36 \pm 0.03$ & $0.26 \pm 0.03$ & $0.19 \pm 0.04$ & $0.16 \pm 0.04$ \\
& $(0.3-0.31)$ & $(0.29-0.23)$ & $(022-0.14)$ & $(0.21-0.13)$ \\
1.250 & $0.18 \pm 0.02$ & $0.13 \pm 0.02$ & $0.06 \pm 0.03$ & $0.03 \pm 0.01$ \\
& $(0.2-0.16)$ & $(0.16-0.11)$ & $(0.09-0.02)$ & $(0.4-0.01)$ \\
& $0.02 \pm 0.02$ & $0.00 \pm 0.00$ & $0.00 \pm 0.00$ & $0.00 \pm 0.00$ \\
5 & $(0.05-0.01)$ & $(0.00 \pm 0.00)$ & $(0.00 \pm 0.00$ & $(0.00 \pm 0.00$ \\
10 & $0.00 \pm 0.00$ & $0.00 \pm 0.00$ & $0.00 \pm 0.00$ & $0.00 \pm 0.00$ \\
& $0.00 \pm 0.00$ & $0.00 \pm 0.00$ & $0.00 \pm 0.00$ & $0.00 \pm 0.00$ \\
\hline
\end{tabular}

Table 4. In vitro inhibition rate of Trypanosoma brucei by crude aqueous extract of Carica papaya leaf

\begin{tabular}{lllll}
\hline \multirow{2}{*}{$\begin{array}{l}\text { Concentration of Extract } \\
(\mathrm{mg} / \mathrm{ml})\end{array}$} & \multicolumn{4}{c}{ \% Inhibition Minutes Post Inoculation (Mean \pm SD) } \\
\cline { 2 - 4 } & $30 \mathrm{mins}$ & $60 \mathrm{mins}$ & $90 \mathrm{mins}$ & $120 \mathrm{mins}$ \\
\hline PBGS (Control) & $00 \pm 00$ & $00 \pm 00$ & $00 \pm 00$ & $00 \pm 00$ \\
0.078 & $67.66 \pm 2.88$ & $71.86 \pm 4.49$ & $72.99 \pm 2.76$ & $75.50 \pm 1.36$ \\
& $(70.77-64.87)$ & $(77.56-68.11)$ & $(70.33-19.2)$ & $(97.74-74.15)$ \\
0.156 & $73.26 \pm 1.17$ & $76.18 \pm 2.26$ & $83.11 \pm 1.77$ & $85.49 \pm 0.44$ \\
& $(73.86-72.13)$ & $(79.02-73.51)$ & $(85.71-89.91)$ & $(85.53-85.00)$ \\
0.131 & $78.68 \pm 284$ & $83.35 \pm 1.94$ & $87.34 \pm 0.71$ & $89.66 \pm 0.98$ \\
& $(81.87-77.44)$ & $(84.88-80.51)$ & $(88.16-86.67)$ & $(91.06-0.98)$ \\
& $81.29 \pm 1.38$ & $86.0 \pm 0.77$ & $90.95 \pm 2.23$ & $93.83 \pm 2.99$ \\
1.625 & $(83.24-80.00)$ & $(87.577-85.85)$ & $(94.29-89.74)$ & $(98.05-91.06)$ \\
& $91.82 \pm 0.97$ & $94.58 \pm 0.64$ & $97.23 \pm 1.14$ & $98.93 \pm 0.48$ \\
2.5 & $(92.97-90.81)$ & $(95.18-93.08)$ & $(97.98-96.10)$ & $(99.58-98.54)$ \\
& $99.22 \pm 1.22$ & $100 \pm 0.00$ & $100 \pm 0.00$ & $100 \pm 0.00$ \\
& $(100-97.44)$ & & & \\
\hline
\end{tabular}

PBGS = phosphate buffered glucose solution; MPI = minutes post inoculation.

A. A. Biu and others 
The phytochemical screening of aqueous extract of Carica papaya revealed the presence of flavonoids, alkaloids, steroids, monosaccharides, reducing sugars, phlabotannins, free anthraquinones and glycosides while saponins was not detected. Mello et al. (2008) reported similar phytochemical compounds from $C$. candamascensis. The median lethal dose $\left(\mathrm{LD}_{50}\right)$ of the leaf crude extract was calculated as $600 \mathrm{mg} / \mathrm{Kg}$. This falls within the range between 500 to $1000 \mathrm{mg} / \mathrm{Kg}$ which has been classified as moderately toxic (Hodge and Sterner, 1949). It has been reported in several studies that toxicity is related to the effects of the extracts on the liver, kidney and other functional organs of animals by altering their specific enzymes (Bruno et al., 2013). The in vitro efficacy of the extract on T. brucei at different concentrations in this study revealed $100 \%$ inhibition of motilily at concentrations of $2.5 \mathrm{mg} / \mathrm{ml}$ and above. This agrees with Sepulveda-Boza and Cassels (1996) that many natural products exhibit their trypanocidal effect by acting either on the respiratory chain or on the cellular defences against oxidative stress. This also confirms with the reports of Bruno et al. (2013), which indicated that the trypanocidal activities affects different targets or biologically significant processes in the parasite, generate intra-parasitic toxic radicals through 5-nitrofuryl moiety and inhibition of cruzipain through the thiosemicarbazone pharmacophore. It is also known that some agents act by binding with kinetoplast DNA of trypanosomes (Beiyu et al., 2006).

In conclusion, results from this study have shown that crude aqueous extract of Carica papaya leaf contained important secondary metabolites, moderately toxic in rats and has in vitro trypanosomal inhibitory action.

\section{REFERENCES}

1. Aliu YO and Nwude NI (1982). Veterinary Pharmacology and Toxicology Experiments. ABU Press, Zaria, Nigeria. pp. 104-110.

2. Beiyu L, Henrik M, Dario K, Akhilesh P and Paul T (2006). Role of p38 in replication of Trypanosoma brucei kinetoplast DNA. Journal of Molecular Cell Biology 26: 5382.

3. Brun R, Blum J, Chappuis F and Burri C (2010). Human African trypanosomiasis. Lancet 379: 148-159.

4. Bruno D, Miriam R, Francesco C, Daniel L and Claudio O (2013). Potential mechanism of the anti-trypanosomal activity of organoruthenium complexes with bioactive thiosemicarbazones. Biological Trace Element Research 153: 371-381.

5. Herbert WJ and Lumsden WH (1976). Trypanosoma brucei method of estimating the host's parasitemia. Experimental Parasitology 40:427-431.

6. Hodge HC and Sterner JH (1949). Toxicity Rating. American Industrial Hygiene Association Quarterly 10: 93-96. Doi: 10.1080/00968204909344159.

7. Hoet S, Stevingy C, Block S and Baldeyrov B (2004). Antitrypanosomal activity, cytotoxicity and interaction with DNA and poisomerase. Plant Medicine 70: 405-513.

8. Mello VJ, Gomes MT, Lemos FO and Delfino JL (2008). The gastric ulcer protective and healing role of cysteine proteinases from Carica candamascensis. Journal of Phytomedicine 15: 237-244.

9. Moore AC (2005). Prospects for improving African trypanosomiasis chemotherapy. Journal of Infectious Diseases 191: 1793-1795.

10. Munox V, Sauvain M, Bourdy G, Callaba J, Rojas I, Tae A and Deharo E (2000). The search for natural bioactive compounds through a multidisciplinary approach in Bolivia. Journal of Ethanophamacology 69: 139-155.

11. Rocha G, Martins A, Gama G and Brandco F (2004). Possible causes of sexual and congenital transmission of sleeping sickness. Lancet 363: 247.

12. Sepulveda-Boza S and Cassels BK (1996). Plant metabolite active against Trypanosoma cruzi. Journal of Medicine 62: 98-105.

13. Sofowora A (1993). Medicinal Plants and Traditional Medicine in Africa. $2^{\text {nd }}$ Ed. Spectrum Books Ltd., Ibadan, Nigeria. pp. 134-156.

14. Tyler KM and Steverding D (2005). Novel Anti-trypanosomal agents. Expert opinion on Investigational Drugs 14: 939-955.

15. Trease GE and Evans WC (2002). Pharmacognosy. $15^{\text {th }}$ Ed. Saunders. pp. 214-393. 